\title{
Left tracheal sleeve pneumonectomy: A combined approach
}

\author{
David G. Tse, MD, ${ }^{a}$ Nippon Vadehra, MD, and Luiza lancu, MD, ${ }^{\mathrm{c}}$ West Los Angeles, Calif
}

$\mathrm{L}$ eft tracheal sleeve pneumonectomy is an uncommon operation in lung cancer surgery. Although resection is complex, cure can be achieved for localized disease. Singlestage surgical approaches include left posterolateral thoracotomy, bilateral anterolateral thoracotomy, and median sternotomy with or without left anterolateral thoracotomy. We report a successful approach incorporating right posterolateral thoracotomy, endobronchial stenting, and video-assisted thoracoscopic surgery (VATS).

\section{Clinical Summary}

A healthy 38-year-old man had decreased breath sounds of the left hemithorax during preoperative physical examination for vasectomy reversal. The patient had had three episodes of left lung pneumonia in the previous 4 years. Chest radiographic images revealed a hyperlucent left hemithorax. A computed tomographic scan showed a tumor with extraluminal penetration of the left main stem bronchus extending within $7 \mathrm{~mm}$ of the bifurcation of the upper and lower lobe orifices (Figures 1 and 2). No hilar or mediastinal adenopathy was seen. Preresection rigid bronchoscopy with biopsy samples taken showed a bulky, obstructive, sessile carcinoid tumor on the left lateral wall originating at the level of the carina. Attempts to improve airway patency with an Nd:YAG laser were halted because of bleeding.

At surgery, a $12 \times 14$-mm Nitinol Ultraflex Noncovered Microvasive Stent (Boston Scientific, Natick, Mass) was inserted into the left main stem bronchus. This procedure successfully restored sufficient luminal diameter to allow ventilation of the left lung with a right-sided double-lumen endotracheal tube. Single-lung ventilation facilitated optimal exposure for complete pericardial hilar release, subcarinal lymph node dissection, and carinal resection through a right-sided posterolateral thoracotomy. Exposure for the anastomosis remained excellent as ventilation of the left lung through the right hemithorax was continued through a cross-field, armored endotracheal tube placed within the stent. The left main stem bronchus was sewn closed after removal of the flexible stent. VATS left pneumonectomy with mediastinal lymph node dissection through three $1.2-\mathrm{cm}$ incisions and one $4.5-\mathrm{cm}$ incision could be performed because ventilation was provided by the right lung. The left pulmonary artery and veins were dissected and individually ligated. The left lung was

From the Divisions of Thoracic Surgery, ${ }^{\mathrm{a}}$ Anesthesiology, ${ }^{\mathrm{b}}$ and Pulmonary Medicine, ${ }^{\mathrm{c}}$ Kaiser Permanente Medical Center, West Los Angeles, Calif.

Received for publication April 20, 2004; accepted for publication May 21, 2004.

Address for reprints: David G. Tse, MD, Department of Thoracic Surgery, Kaiser Permanente Medical Center, 6041 Cadillac Ave, West Los Angeles, CA 90034 (E-mail: david.g.tse@kp.org).

J Thorac Cardiovasc Surg 2005;129:454-5

$0022-5223 / \$ 30.00$

Copyright $\odot 2005$ by The American Association for Thoracic Surgery

doi:10.1016/j.jtcvs.2004.05.031

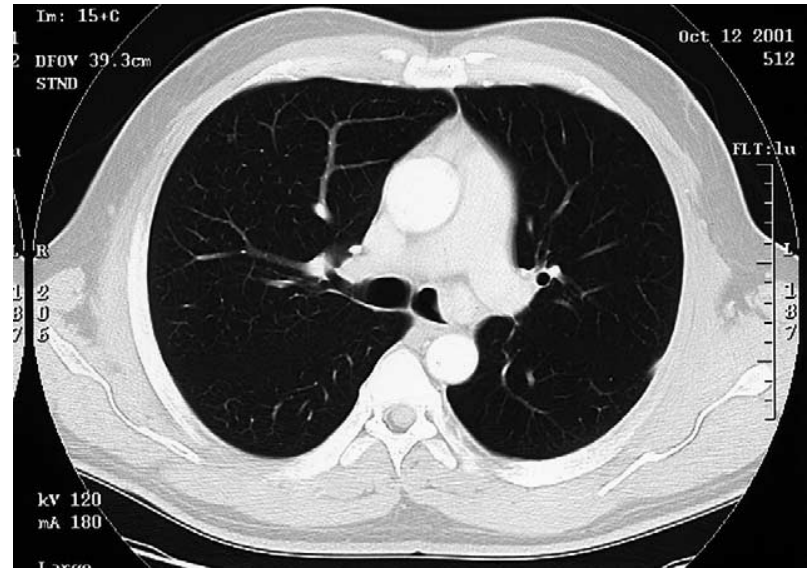

Figure 1. Computed tomographic scan shows carcinoid tumor of left main stem bronchus at carinal level with bronchial wall infiltration.

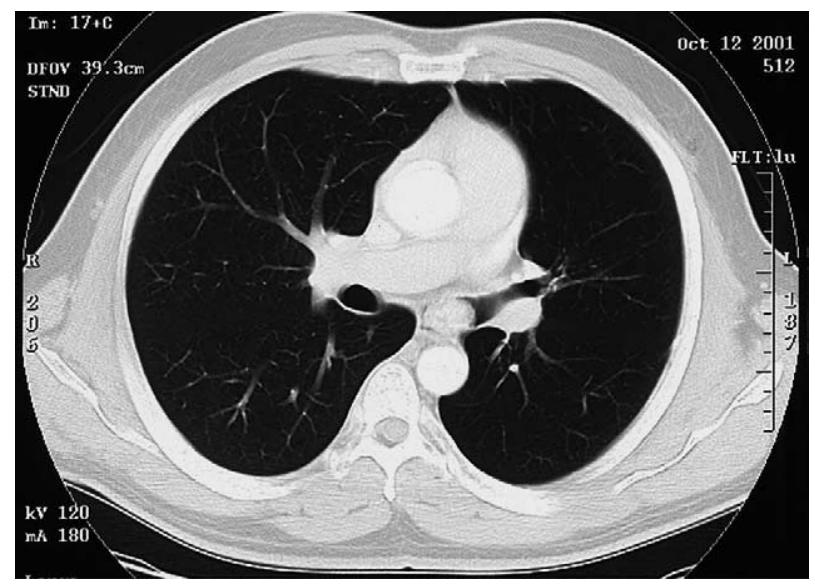

Figure 2. Computed tomographic scan shows distal extent of tumor adjacent to bifurcation of left upper lobe orifice.

inserted into a Lapsac cloth bag (Cook Urological, Spencer, Ind) and removed through the 4.5 -cm fourth intercostal space incision without rib spreading. Pathology examination revealed a bulky typical carcinoid tumor penetrating the bronchial wall. Hilar and mediastinal lymph nodes showed no evidence of metastases. The anastomosis was patent at 6 weeks, and the patient has remained well $2 \frac{1}{2} 2$ years after the procedure.

\section{Comment}

Tracheal sleeve pneumonectomy is a complex operation, with reported operative mortality ranging from $15 \%$ to $27 \% .^{1,2} \mathrm{Left}$ tracheal sleeve pneumonectomy is an uncommon operation in lung 
cancer surgery. Bronchial sleeve resection for conservation of unaffected lung parenchyma is preferable — and would be idealfor main stem bronchial tumors; however, for tumors affecting a large part of the left main bronchus, division of the bronchus close to the bifurcation of the upper and lower lobes precludes tracheal bronchial anastomosis. ${ }^{3}$

Controversy exists regarding the best surgical approach for left tracheal sleeve pneumonectomy and whether or not a single- or two-stage operation should be performed. ${ }^{4}$ Single-stage surgical approaches include left posterolateral thoracotomy, median sternotomy with or without left anterolateral thoracotomy, ${ }^{5}$ and bilateral anterolateral thoracotomy. ${ }^{6}$ The success of any approach depends on several principles: optimal exposure, avoidance of anastomotic tension, preservation of airway vascular supply, and adequate ventilation and oxygenation.

Excellent exposure for distal tracheal-right main stem bronchial anastomosis can be obtained through a right posterolateral thoracotomy. We performed tension-releasing maneuvers, subcarinal lymph node dissection, carinal resection, and tracheobronchial anastomosis through this approach. Adequate ventilation and oxygenation were maintained by the left lung with cross-field ventilation through the right side of the chest and were made possible through use of a nitinol endobronchial stent. Although self-expanding metallic stents are more commonly used as a durable solution in management of malignant airway obstruction, temporary use of such a stent in this case obviated the need for alternative methods of ventilation and oxygenation (cross-field ventilation through the right bronchus, jet ventilation, or cardiopulmonary bypass). In addition, VATS left pneumonectomy was used as a progressive alternative to traditional left posterolateral or anterolateral thoracotomy for completion of left pneumonectomy. The oncologic principles of complete resection and lymph node dissection can be maintained while minimizing the extent of tissue trauma and postoperative pain with techniques of VATS. Advances in endosurgical techniques and videoendoscopic instrumentation will continue to foster broader application of VATS in thoracic surgery.

We thank The Kaiser Foundation Medical Editing Department for editorial assistance.

\section{References}

1. Mitchell JD, Mathisen DJ, Wright CD, Wain JC, Donahue DM, Allan JS, et al. Resection for bronchogenic carcinoma involving the carina: long-term results and effect of nodal status on outcome. J Thorac Cardiovasc Surg. 2001;121:465-71.

2. Faber LP. Results of surgical treatment of stage III lung carcinoma with carinal proximity. The role of sleeve lobectomy versus pneumonectomy and the role of sleeve pneumonectomy. Surg Clin North Am. 1987;67: 1001-14.

3. Mathisen DJ, Grillo HC. Carinal resection. In: Pearson FG, Hiebert CA, Deslauriers J, McKneally MF, Ginsberg RJ, Urschel, HC Jr, editors. Thoracic surgery. New York: Churchill Livingstone; 1995. p. 345-54.

4. Deslauriers J, Jacques LF. Sleeve pneumonectomy. Chest Surg Clin N Am. 1995;5:297-313.

5. Dartevelle P, Macchiarini P. Techniques of pneumonectomy. Sleeve pneumonectomy. Chest Surg Clin N Am. 1999;9:407-17, xi.

6. Maeda M, Nakamoto K, Tsubota N, Okada T, Katsura H. Operative approaches for left-sided carinoplasty. Ann Thorac Surg. 1993;56:441-6. 